\title{
Individualism/Collectivism and Academic Self-Enhancement in New Zealand Māori University Students
}

\author{
Natasha A. Tassell, Ross A. Flett, and Jhanitra R. Gavala
}

\begin{abstract}
$\mathrm{T}_{\mathrm{N}}^{\mathrm{n}}$ he present study had several aims: to examine horizontal/vertical individualism/collectivism in a New Zealand Māori sample; to determine whether these cultural orientations contribute to academic self-enhancement; and to investigate if self-enhancement affects intentions to continue studies in higher education. A quantitative questionnaire was distributed to a nonprobability convenience sample of 71 Māori university students. All participants had either studied within the past year or were currently studying, and were recipients of a Māori-specific bursary for higher education studies. Results revealed the sample scored high on measures of horizontal collectivism and academic selfenhancement. ANOVAs showed some significant differences between our sample and other cultural samples on some of the cultural orientations. A series of standard multiple regressions revealed that combined, the cultural orientations predicted academic self-enhancement, although only horizontal collectivism made a significant negative contribution. Academic intentions were not predicted by selfenhancement. The findings have implications for policy development and educational strategies oriented toward enhancing the academic success of Māori in higher education.
\end{abstract}

Keywords: individualism, collectivism, self-enhancement, Māori, indigenous

The constructs of individualism and collectivism are the most widely studied characteristics of culture (Brewer \& Chen, 2007; Green, Deschamps, \& Paez, 2005; Singelis, Bond, Sharkey, \& Siu Yiu Lai, 1999). Believed to constitute two distinct and universal patterns (Triandis \& Gelfand, 1998; Triandis \& Suh, 2002), they explain and capture some factors determining cultural differences (Brewer \& Chen, 2007; Greenfield, 1999), and influence a variety of processes governing individual functioning, including self-enhancement. Defined as a 'mechanism that protects one's self-concept from negative information' (Kurman, Yoshihara-Tanaka, \& Elkoshi, 2003, p. 25) through the preservation of subjectively positive beliefs and emotions, self-enhancement was originally believed to manifest according to the individualist or collectivist orientation characterising a culture.

Individualism is characterised by a tendency to see the self as unique, bounded and separate from other selves, and striving to achieve personal goals and ambitions. Maintaining a positive view of one's abilities and traits would seem imperative to this aim, so self- enhancement may be important in individualistic cultures. Collectivists see the self in relation to significant others, placing the needs, wants and desires of the group before personal aims and ambitions. Focusing on one's positive qualities may take emphasis away from the group, so self-enhancement may not be necessary for individuals in such cultures.

The focus of the present article is to advance understanding of the universality of individualism and collectivism, by examining their prevalence in a sample of New Zealand Māori. We argue the values, beliefs and traditions of this indigenous culture reflect horizontal collectivism. Following the work of Markus and Kitayama (1991) and more recently Kurman and Sriram (2002), we examine the relationship between individualism/collectivism and academic self-enhancement. Self-enhancement is a basic motivating factor of the self (Kurman, 2001), so when applied to an academic context, it may be useful as a potential explanation for the current representation of Mā ori in higher education environments. 


\section{Individualism and Collectivism}

Individualism and collectivism are the most predominantly studied characteristics of culture (Brewer \& Chen, 2007; Green et al., 2005; Singelis et al., 1999). The individualist cultural pattern results when individuals view themselves independently. The self is bounded, distinct and separate from other selves, and defined in terms of its' unique personal attributes, traits, and characteristics. The individual controls behaviour, initiating actions to fulfil needs, wants, and desires. While not separated entirely from the in-group, relationships with others are voluntary and exist primarily to meet one's needs (Harrington \& Liu, 2002; Markus \& Kitayama, 1994). Individualist cultures encourage and promote autonomy and independence of individuals (Jetten, Postmes, \& Mcauliffe, 2002; Markus \& Kitayama, 1994; Schwartz, 1990; Strunk \& Chang, 1999).

The collectivist cultural pattern results when the self is viewed interdependently, and individuals define themselves by their relationships with and connectedness to significant others (Harrington \& Liu, 2002). Primary importance is given to collectively beneficial actions, with the objective of maintaining harmonious, mutually beneficial relations and feelings of interdependence (Jetten et al., 2002; Markus \& Kitayama, 1994). Others' reactions are considered before the needs, wants, and desires of the self, which become secondary to the needs, wants, and desires of others (Atwater, Wang, Smither, \& Fleenor, 2009; Kashiyama et al. 1995; Markus \& Kitayama, 1991). Collectivist cultures encourage interdependence with and obligation to significant others (Oyserman, Coon, \& Kemmelmeier, 2002).

Although individualism and collectivism were originally conceptualised as distinct extremes on a continuum, Triandis (1990, 1995) observed these orientations manifest differently in different cultures. Individualism in America differs from that in Sweden. Korean collectivism is different from the Israeli kibbutz (Triandis \& Gelfand, 1998). This led to the proposition that individualism and collectivism are multidimensional, comprising two suborientations: vertical and horizontal. Verticality is characterised by hierarchy and differentiation. Horizontalism is typified by equality and similarity (Gushue \& Constantine, 2003; Nelson \& Shavitt, 2002; Triandis \& Gelfand, 1998). Verticality and horizontalism combine with individualism/collectivism to form four distinct characteristics of culture.

In cultures characterised by horizontal individualism (HI), individuals want to be independent and distinct from their in-group, but do not wish to acquire any particular hierarchical status. Uniqueness, while still maintaining a sense of equality with others is the focus (Triandis \& Gelfand, 1998). Vertical individualists (VI) wish to remain independent and unique. They are oriented toward achieving status and hierarchy, often succeeding through competition with others. In horizon- tal collectivist (HC) cultures, an orientation toward interdependence, similarity, and equality exists among individuals. Importance is placed on group goal achievement, which is attained through cooperativeness of group members rather than compliance to authority figures. Vertical collectivists (VC) are interdependent, placing particular significance on in-group integrity. They tend to be dutiful, often forsaking individual goals for those of the in-group (Gouveia, Clemente, \& Espinosa, 2003; Nelson \& Shavitt, 2002; Triandis \& Gelfand, 1998).

Evidence for these cultural orientations has been found cross-culturally. Gouveia et al. (2003) observed a sample of Spanish participants scored higher on horizontal collectivism than on vertical individualism, suggesting participants were interdependent, but placed importance on equality among individuals rather than hierarchy. Spanish society places strong emphasis on hospitality, friendliness, respect, harmonious relationships (Triandis, Marin, Lisansky, \& Betancourt, 1984), and communal sharing (Fiske, 1992).

Singaporeans scored higher on vertical collectivism, in comparison to Kibbutz Israeli, Urban Israeli and American samples (Kurman \& Sriram, 2002; Soh \& Leong, 2002). Singapore has a Chinese majority, and many of the values inherent to this island nation derive from this group. Singaporean Chinese place importance on in-group relations and respect for social hierarchy. Israeli Kibbutz communities are founded on the philosophy of equality among in-group members, and hierarchy within the community is actively avoided (Kurman \& Sriram, 2002).

Americans scored higher on vertical individualism and Danes scored higher on horizontal individualism, in a study by Nelson and Shavitt (2002). Danish society is structured around a social welfare system, which emphasises benevolence toward less-fortunate individuals and equality with regard to social standards of living. In contrast, the United States is typically categorised as an individualistic society, where competition exists between individuals and progression according to hierarchical status is emphasised (Triandis, 1995). The results of this study map onto the values perceived to underpin these cultures.

In their meta-analysis, Oyserman et al. (2002) suggested such findings may not be as conclusive as they appear with regard to the categorisation of individualism/collectivism and verticality/horizontalism. The samples typically used in such research have been American or Western European and East Asian (predominantly Japanese, Hong Kong, Korean, and Peoples Republic of China), or minority groups in the United States (e.g., African Americans, Asian Americans, Latin Americans). Such restricted sampling raises doubts about the universality of the orientations, and makes it difficult to ascertain whether the cultural orientation of ethnic groups residing in different nations is the same type of 
individualism/collectivism and verticality/horizontalism evidenced in American and East Asian samples.

Contradicting this criticism, some studies show evidence of the four cultural orientations in non-American and non-East Asian samples. Thomas and Perkerti (2003) revealed a sample of New Zealand employees had a cultural profile characteristic of horizontal individualists. Bochner (1994) showed Australian and British participants were more individualistic than Malaysian participants, who were more collectivistic. Urban Israeli's scored higher on measures of individualism in comparison to kibbutz Israeli's who scored higher on horizontal collectivism (Kurman \& Sriram, 2002), indicating cultural differences within nations exist also.

These cultural orientations need further investigating before definitive conclusions regarding universality can be made. Given the heterogeneity of modern societies and cultures, the distinct categorisations of individualism and collectivism cannot apply to individuals in all cultures. Many individuals are likely to exhibit both cultural orientations, albeit to varying degrees (Green et al., 2005). Acculturation of some ethnic groups undoubtedly led to intra-group variations in cultural orientations (Hartung, Fouad, Leong, \& Hardin, 2010). Cultural orientations vary according to socio-economic circumstances in some majority groups (OzdikmenliDemir \& Sayil, 2009).

Additionally, the orientations may comprise more than the sub-categorisations of verticality and horizontalism, and extend to constructs such as competitiveness, harmony, and responsibility (e.g., Brewer et al., 2007; Shulruf et al., 2007). In this sense, the extent definitive statements can be made about individualism/ collectivism may be still somewhat limited. The constructs of individualism/collectivism may be catalysts for discussing, investigating and developing a greater appreciation for the many unique diversities existing between cultures of the world.

Despite these potential limitations, significant relationships have been observed between vertical/horizontal individualism/collectivism and a variety of psychological variables, such as embarassability (e.g., Singelis et al., 1999), authoritarianism (e.g., Kemmelmeier et al., 2003), and self-enhancement (e.g., Kurman, 2003; Kurman \& Sriram, 2002). Self-enhancement has been increasingly researched, with levels tending to be higher in individualist samples compared to collectivist samples (e.g., Kurman, 2001, 2003), while other studies suggest vertical and horizontal distinctions may play a role (e.g., Kurman \& Sriram, 2002). Therefore, an exploration of the selfenhancement concept is necessary.

\section{Self-Enhancement}

Self-enhancement is defined as a 'mechanism that protects one's self-concept from negative information' (Kurman et al., 2003, p. 25) through the preservation of subjectively positive beliefs and emotions, irrespective of their objective nature. Research examining self-enhancement typically explores the ways individuals rate themselves with regard to specific traits or behaviours, and compares these with objective measures (Heine \& Lehman, 1997). Results show most people rate themselves more positively than objective measures would indicate. Protecting oneself from negative information and maintaining a positive view of the self is beneficial. Self-enhancement positively influences emotional and psychological functioning (e.g., Bonanno, Rennicke, \& Dekel, 2005; Kitayama, Markus, \& Kurokawa, 2000; Snibbe, Kitayama, Markus, \& Suzuki, 2003).

Self-enhancement and psychological wellbeing were examined in samples of Singaporean Chinese and urban Israeli high school students; Israeli and Singaporean college students; Japanese and Israeli university students; and students who were either Israeli-born or Israeli of Ethiopian origin (Kurman, 2003). Results showed selfenhancement had significantly positive relationships with psychological wellbeing and self-esteem. Bonanno et al. (2005) examined whether self-enhancement predicted adjustment in survivors of the 9/11 attack in New York city. Findings revealed better adjustment, positive affect, and resilience were predicted by self-enhancement.

Kobayashi and Brown (2003) assessed how important Japanese and American participants with high- or low self-esteem thought it was for any person, themselves, their best friend, and most students at their university to possess eight attributes (i.e., competent, friendly, modest, persistent, responsible, well-liked, value friendship, and enjoy life with regard to recreation, work, and family). Results indicated both American and Japanese individuals with high self-esteem demonstrated self-enhancement, although the direction of the causal relationship is uncertain. Irrespective, the results suggest the psychological benefits of maintaining a positive view of the self.

Cross-cultural differences in the tendency to selfenhance have been increasingly reported in the literature, suggesting the construct may not be applicable to all cultures. A meta-analysis by Heine and Hamamura (2007) found East Asians did not show a self-serving bias, were self-critical, and were less likely to self-enhance in comparison to Westerners. In line with suggestions of previous researchers (e.g., Heine, Kitayama, \& Lehman, 2001; Heine, Lehman, Markus, \& Kitayama, 1999; Markus \& Kitayama, 1991; Snibbe et al., 2003), the findings also suggested in many East Asian countries self-enhancement exists, but is expressed at lower levels in comparison to individualist cultures, such as America and many Western European countries. Given the significant and positive relationships with emotional adjustment, psychological wellbeing and other behaviours (e.g., selective memory, cognitive dissonance), self-enhancement must be essential to beneficial functioning and thus exist in all 
cultures. However, individualist or collectivist orientations of the culture determine the degree or level of expression of self-enhancement.

Self-enhancement should be actively expressed in individualist cultures, as the self is viewed and defined in terms of unique characteristics and independence, so maintaining positive information about oneself serves a purpose. Alternatively, relationships and connectedness to others define collectivist societies. Self-enhancement would still be experienced internally as it serves a purpose for individuals (e.g., emotional functioning, psychological functioning, selective memory), but its expression should be restricted as it serves no obvious external objective for the individual.

Criticisms of the self-enhancement literature typically highlight the limited range of populations sampled. As with individualism/collectivism research, American and East-Asian cultures tend to predominate as study samples (Church et al., 2006). An aim of this research is to move beyond this criticism by assessing the relevance of self-enhancement in a population that has not knowingly been sampled previously - New Zealand Māori. An overview of this cultural group, and predictions regarding the prevalence of individualism/collectivism, verticality/horizontalism, and self-enhancement is given in the following section.

\section{New Zealand Māori}

Despite being the indigenous culture of Aotearoa / New Zealand, Māori are now a numerical minority, constituting $14.6 \%$ of the total country population according to the 2006 census (Statistics New Zealand, 2007). Decades of 'colonisation, exploitation, and oppression' (Walker, Eketone, \& Gibbs, 2006, p. 332) led to the erosion of many Māori cultural institutions, including language and traditions, and the diversification of Māori ways of being and living. Given the cultural variation of the contemporary New Zealand population, modern Māori are now as diverse as other New Zealanders (Bennett, 2001).

Due to colonisation, education, experience with racism, lack of access to culturally knowledgeable people, among other things, traditional or old-time values are not necessarily meaningful for all Māori. Urban dwellers may be hindered more than rural dwellers from the 'living' out of these values. Mãori youth may live in ways more reflective of a global youth culture, rather than traditional Māori culture (Durie, 2008). Some Māori strongly endorse concepts of Christianity more than traditional Māori values as being important, while others combine both worlds, or do not endorse either (Elsmore, 1989).

Despite the 'diverse realities' of modern Māori (Durie, 2008), many traditional values are still recognised as important and uniquely characteristic of Māori culture. We suggest the values, traditions and beliefs underpinning Māori culture emphasise interdependence with and equal- ity between group members, and propose Māori individuals show an inclination toward horizontal collectivism. To better explicate this claim, an examination of the underlying values of Māori culture is necessary.

Perhaps the most important value is whanaungatanga, which relates directly to family (whānau). Whanaungatanga emphasises interdependence and obligation, not only among family members, but also with associated groups such as the tribe (iwi) and subtribe (hapu $\bar{u}$ (Henare, 1988; Metge, 1995). Interactions among members are expected to be mutually beneficial, which creates a sense of connectedness between people and emphasises the needs of the collective, as opposed to the individual. While this value is intimately tied to family and wider kin-relations, it may also extend outside of kin-relations to groups or individuals sharing family-like relations or activities. For example, whanaungatanga may be exercised between members of sports teams, school committees, and various hobby groups.

Complementary to whanaungatanga is the concept of kotahitanga. Translated as oneness, it implies advancement of the Māori people can only be achieved through the collective efforts of all members of the culture (Henare, 1988). Participation in whānau, iwi, or hapū development varies, and some individuals are more or less active than others (P. Hirini, personal communication, July 1,2004$)$. However, there is often an expectation that at some stage all members of the culture will contribute toward the collective, which may involve subordinating their own needs to cater to their culture.

Tohatoha refers to the fair distribution of material things among members of the culture (Henare, 1988). This value is actively practiced by many Mãori and is an extension of the value of kotahitanga. One of the most frequent examples of tohatoha involves the sharing of resources across uniquely Māori social institutions, such as funerals (tangihanga) and formal gatherings (hui). The main premise of this value is that each member of Māori culture has a social responsibility to all others.

The value of social reciprocity, or $u t u$, refers to social balance within Māori society. It implies anything received must be repaid incrementally, at an appropriate time. While the recipient may be an individual, other family members may feel some responsibility for repayment, and make personal sacrifices to guarantee the obligation is fulfilled (Henare, 1988; Metge, 1995). This creates an opportunity for relationships between members of the Māori culture to begin or continue in a harmoniously self-perpetuating fashion, both for present and future generations.

The final value is mana, which very generally refers to authority, social status, or integrity (Durie, 2001). When an individual is perceived as possessing specific traits that foster the wellbeing of the collective, mana is believed inherent in them. It is for others to bestow mana, so an individual cannot proclaim they possess this 
value as this would be considered a sign of arrogance (whakahihi). Instead, modesty about one's achievements (whakaiti) is encouraged. Being perceived as a person with mana is best understood within the context of an individual's harmonious and beneficial relationships to whānau, hapū, and iwi (Henare, 1988). In this sense, mana may also be perceived as a trait inherent to an individual, as acting out the principals of mana are in line with living life in accordance with specified values and ways of acting. Mana can exist outside of the Māori milieu, with some Pākehā being perceived as possessing mana, due to benevolent acts performed in the service of others.

Overall, these values appear to map closely onto collectivist characteristics (e.g., importance placed on unity, connectedness and relationships to significant others, collectively appropriate behaviours, own needs secondary to others), and more specifically the values of whanaungatanga, kotahitanga, tohatoha and utu reflect a horizontal orientation (i.e., significance placed on ingroup integrity, equal distribution of resources, forsaking individual goals for the group). However, given the diverse realities of modern Māori, it should be noted these values may be acted out without individuals actually knowing the exact term for the expression of values. Despite this, the characteristics of such values reflect horizontal collectivism, and we propose Māori as a cultural group are likely to endorse this cultural orientation.

Previous research is inconclusive regarding whether Māori are more individualistic or collectivistic as a cultural group, and whether they differ in cultural orientation to other cultural groups in New Zealand. Hewson (2002) found no significant difference in cultural orientation between Māori and Pākehā. Harrington and Liu (2002) found Māori are more oriented to collectivism compared to Pakeha. Shulruf, Hattie, and Dixon (2007) found similar results on the cultural orientations for Māori and Pākehā .

To better explicate these studies, and following from previous work (e.g., Kurman \& Sriram, 2002; Nelson \& Shavitt, 2002; Thomas \& Perkerti, 2003), we assessed cultural orientations in a sample of New Zealand Māori university students, and whether there were any significant differences between our sample and other cultural samples. Oyserman et al. (2002) found inconsistent effect sizes in East Asian individualism/collectivism studies, suggesting Asian samples do not share the same degree of cultural orientation, as is often assumed. We suspect this is also likely to apply to the present sample. Māori may not share the same degree of horizontal collectivism as previously studied samples, as the values inherent to Māori culture may mean this orientation manifests in different ways. However, it is possible there will be similarities to other cultural groups characterised by horizontal collectivism.
A further aim of this study is to assess whether selfenhancement is pertinent to New Zealand Māori. Previous research shows self-enhancement tends to be higher in individualist cultures, in comparison to collectivist cultures (e.g., Kurman 2001, 2003). We propose New Zealand Māori are more likely to be a horizontal collectivist culture, so the findings of low self-enhancement noted in other collectivist cultures may also be apparent in Māori culture. A study by Kurman and Sriram (2002) showed horizontal collectivism was not significantly associated with self-enhancement. Māori culture places importance on equality, cohesion, and the wellbeing of the collective, as opposed to the individual. It also frowns upon exalting one's personal attributes. With this in mind and in line with the findings of Kurman and Sriram (2002), self-enhancement is not expected to be an important outcome for our sample.

A final aim is to discuss the relevance of academic self-enhancement to Māori participation in higher education. Māori participation rates currently exceed those of other ethnic groups in New Zealand, although overall less than a quarter of all Māori participate in higher education (Ministry of Education, 2007). We propose self-enhancement will be low in our sample of Māori university students, and this will affect intentions to continue in an academic higher education environment. Specifically, academic self-enhancement involves maintaining a positive view of one's academic abilities and achievements. Individuals possessing such positive views are more likely to continue in higher education academic environments as they believe they are well equipped to do so. We predict our participants will be low on selfenhancement, so perceptions regarding one's positive abilities are unlikely to be a motivating factor for staying in an academic environment.

\section{Method}

Participants

A nonprobability convenience sample collected through the acquaintanceship networks of the first author comprised the pool of participants. A total of 71 participants of Māori descent took part in the research, representing a response rate of $56 \%$.

Just over three quarters (78\%) of the participants were female, and $45 \%$ were over the age of 40 . Of those participants studying, $41 \%$ were completing undergraduate degrees, while a further $25 \%$ were completing postgraduate degrees. Just over a quarter $(27 \%)$ of participants indicated their highest educational qualification was an undergraduate degree. Equal proportions indicated their highest educational qualification was an undergraduate certificate $(17 \%)$ or a secondary school qualification (17\%).

A total of 47 tribes (iwi) were represented by the sample, with the majority of participants affiliated to Ngāti Porou (20\%), Ngā Puhi (14\%), Ngāti Kahungunu 
(11\%), Ngāti Raukawa (10\%), and Ngāti Maniapoto $(10 \%)$. Just under a quarter were affiliated to Rongomaiwahine, (8\%), Whakatōhea (7\%), or Te Atiawa (7\%). The remaining $13 \%$ of participants represented 39 other tribes.

\section{Procedure}

Participants were recruited via several acquaintanceship networks of the first author. The first of the networks involved accessing students who were bursars of the Te Rau Puawai program at Massey University. Te Rau Puawai is a joint initiative established by Massey University and the Ministry of Health, to support Māori students to gain qualifications in mental health (Mental Health Commission, 2003; Te Rau Puawai, 2004). Participants recruited via this method were all Māori students studying towards a variety of mental health qualifications. Permission to access a mailing list of 110 undergraduate and postgraduate students was granted. The second method involved distributing questionnaires via a snowball method to individuals eligible to participate in the research.

\section{Measures}

Cultural orientations. The 32-item Individualism/ Collectivism scale (Singelis, Triandis, Bhawuk, \& Gelfand, 1995) assessed cultural orientations. This measure has been widely used producing reliable results in studies with a variety of cultural groups (e.g., Gouveia et al., 2003; Kurman \& Sriram, 2002; Nelson \& Shavitt, 2002; Singelis et al., 1995; Soh \& Leong, 2002; Thomas \& Perkerti, 2003). Individualism and collectivism were assessed using 16items each. Example items include: 'I am a unique individual' and 'Winning is everything' for horizontal and vertical individualism, respectively. 'I feel good when I cooperate with others' and 'I hate to disagree with others in my group' respectively measured horizontal and vertical collectivism. Extent of agreement with each item was assessed on a 7-point, Likert-type scale (ranging from $1=$ Strongly disagree to $7=$ Strongly agree). Higher scores on a specific subscale (i.e., vertical/horizontal individualism/ collectivism) indicated dominance of that orientation. Internal consistencies have been reported between .46 to .84 for horizontal individualism; .60 to .76 for vertical individualism; .53 to .85 for horizontal collectivism; and .44 to .80 for vertical collectivism (e.g., Gushue \& Constantine, 2003; Oishi, Schimmack, Diener, \& Suh, 1998; Singelis et al., 1995).

Self-enhancement. Two measures were used. The first consisted of two questions adopted by Kurman (2003) and Kurman and Sriram (2002) assessing academic selfenhancement. Participants were asked 'How successful were you in your [relevant studies] compared to your fellow students?' A 7-point, Likert-type scale (ranging from $1=$ Not successful at all to $7=$ Very successful) assessed level of agreement with the question. The second question asked participants to estimate whether they are generally good students. Responses were made on a 7-point, Likert-type scale $(1=$ I'm a very poor student to $7=$ I'm a very good student), and summed to produce a total overall score. Higher scores for both questions indicated academic self-enhancement. The method adopted by Kurman $(2001,2003)$ assessed the above-average effect, another measure of academic selfenhancement. Participants indicated whether they considered themselves above or below average on six traits (intelligence, health, sociability, cooperation, honesty, and generosity), compared to a population of the same age and gender. Two options were available for responding $(0=$ Above average and $1=$ Below average $)$. Responses were summed to produce an overall score, with lower scores (i.e., 0 to 1 ) indicating an aboveaverage effect. Brown (1998) suggested typically $50 \%$ of samples rate themselves as above-average, although some studies show this rate to be between $74 \%$ to $94 \%$.

Academic intentions. This exploratory 3-item measure assessed the current and future educational intentions of participants. Items included: 'How frequently do you think about leaving your tertiary institution?', 'How likely is it that you will search for another tertiary institution to attend?', 'How likely is it that you will actually leave your tertiary institution within the next year?' A 4-point, Likert-type scale ranging from 1 (Not at all likely) to 4 (Definitely) rated the likelihood of intentions. Lower overall scores indicated an intention to continue studying.

\section{Results \\ Bivariate Analyses}

Table 1 overviews the means, standard deviations and alpha reliabilities across all scales. A high overall mean score on the horizontal collectivism subscale suggests the sample endorsed horizontal collectivism more than the other cultural orientations, which supports our hypothesis Māori are horizontal collectivists. High mean scores on academic self-enhancement mean the sample were likely to self-enhance. Cronbach's alpha data show these measures had acceptable reliability by standard psychometric criteria. The mean score for the above average effect indicates participants considered themselves to be above average on academic traits, and is thus also reflective of self-enhancement. Cronbach's alpha data show this measure did not achieve acceptable reliability by standard psychometric criteria.

\section{Cultural Orientations}

Intercorrelations between the cultural orientations showed horizontal and vertical collectivism had a significantly positive relationship, $r(66)=.55, p<.01$, raising questions about the distinctiveness of the categorisations. The individualist subscales were not significantly correlated, suggesting in this sample the individualism/collectivism measure was assessing these dimensions as distinct. 
Table 1

Scale Data for the Individualism/Collectivism Subscales and Self-Enhancement Scales: Mãori Sample $(N=71)$

\begin{tabular}{|c|c|c|c|c|}
\hline Variable & Scale (score range) & Mean & SD & $\alpha$ \\
\hline Cultural orientations & $\begin{array}{l}\text { HC subscale }(\min =1, \max =7) \\
\text { HI subscale }(\min =1, \max =7) \\
\text { VC subscale }(\min =1, \max =7) \\
\text { VI subscale }(\min =1, \max =7)\end{array}$ & $\begin{array}{l}5.38 \\
3.91 \\
3.38 \\
2.45\end{array}$ & $\begin{array}{l}0.76 \\
0.71 \\
0.66 \\
0.55\end{array}$ & $\begin{array}{l}0.83 \\
0.76 \\
0.68 \\
0.62\end{array}$ \\
\hline Self-enhancement & $\begin{array}{l}\text { Academic Self-Enhancement }(\min =2, \max =14) \\
\text { Above-Average Effect }(\min =0, \max =3)\end{array}$ & $\begin{array}{r}10.20 \\
0.83\end{array}$ & $\begin{array}{l}2.00 \\
0.90\end{array}$ & $\begin{array}{l}0.72 \\
0.26\end{array}$ \\
\hline
\end{tabular}

Comparisons were made on all four cultural orientations, with previously studied collectivist and individualist samples. Table 2 shows comparison with other collectivist samples, all of which scored higher on horizontal subscales than vertical subscales. Overall mean scores on horizontal collectivism were similar across samples. Similar mean scores for the samples were also apparent on the other subscales, with the exception of the Māori sample, who scored markedly lower by comparison. Interestingly, the African American and Asian American samples scored higher on the horizontal individualism subscale than the horizontal collectivism subscale, despite these populations often being perceived as collectivists.

One-way factorial analyses of variance (ANOVA) tested significant differences between the collectivist sample populations on each of the subscales (i.e., HC, HI, VC, VI). Separate ANOVAs showed highly significant effects for the horizontal individualism subscale, $F(4$, $763)=46.70, p<.001$; the vertical collectivism subscale, $F(4,763)=71.27, p<.001$; and the vertical individualism subscale, $F(4,763)=34.29, p<.001$. Effects were nonsignificant for horizontal collectivism, suggesting that when compared to other collectivist cultures the present sample is not significantly different on the horizontal collectivist dimension. A series of post-hoc tests (Tukey's
HSD) were calculated for each significant dependent variable to determine where differences occurred. Results indicated at the $p<.05$ level, significant differences occurred between the Māori sample and other samples, across the HI, VC and VI subscales. The Singaporean, Asian American, African American and Spanish samples did not differ significantly from each other. The findings indicate Māori differ from other samples on the vertical collectivist and both individualist dimensions.

Mean scores for individualist samples are also provided in Table 2. European American samples had higher mean scores on both the horizontal dimensions, showing a similar pattern to our sample. Urban Israeli's scored highest on horizontal individualism, and showed minimal variation in mean scores across the other subscales. Mean scores for the American sample were higher than other samples across all subscales. Higher mean scores were evident for both the collectivist subscales, despite Americans often being perceived as individualists.

Separate ANOVAs for each subscale tested for significant differences between individualist samples. Highly significant effects were found for each of the subscales: horizontal collectivism, $F(3,513)=174.23, p<.001$; horizontal individualism, $F(3,513)=154.56, p<.001$; vertical collectivism, $F(3,513)=246.70, p<.001$; vertical individualism, $F(3,513)=93.71, p<.001$. Post-hoc

Table 2

Means of Various Samples on the Individualism/Collectivism Subscales

\begin{tabular}{|c|c|c|c|c|}
\hline Sample & $\mathrm{HC}$ & $\mathrm{HI}$ & VC & $\mathrm{VI}$ \\
\hline $\begin{array}{l}\text { Māori, } n=71 \\
\text { (present research) }\end{array}$ & $5.38(0.76)$ & $3.91(0.71)$ & $3.38(0.66)$ & $2.45(0.55)$ \\
\hline \multicolumn{5}{|l|}{ Collectivists } \\
\hline $\begin{array}{l}\text { (Kurman \& Sriram, 2002) } \\
\text { African American, } n=23\end{array}$ & $5.32(0.84)$ & $5.30(1.15)$ & $5.80(1.01)$ & $4.19(1.00)$ \\
\hline $\begin{array}{l}\text { (Coon \& Kemmelmeier, 2001) } \\
\text { Asian American, } n=18\end{array}$ & $5.42(0.59)$ & $6.20(0.80)$ & $4.22(0.61)$ & $3.82(1.26)$ \\
\hline $\begin{array}{l}\text { (Coon \& Kemmelmeier, 2001) } \\
\text { Spanish, } n=526\end{array}$ & $5.38(0.65)$ & $5.75(0.80)$ & $4.70(0.70)$ & $4.20(1.13)$ \\
\hline (Gouveia et al., 2003) & $5.48(0.91)$ & $5.23(0.84)$ & $4.60(1.07)$ & $3.21(1.22)$ \\
\hline \multicolumn{5}{|l|}{ Individualists } \\
\hline $\begin{array}{l}\text { (Coon \& Kemmelmeier, 2001) } \\
\text { Urban Israeli's, } n=144\end{array}$ & $5.39(0.68)$ & $5.70(0.80)$ & $4.27(0.80)$ & $4.27(1.05)$ \\
\hline $\begin{array}{l}\text { (Kurman \& Sriram, 2002) } \\
\text { Americans, } n=180\end{array}$ & $4.87(0.98)$ & $5.58(1.00)$ & $4.86(1.58)$ & $4.92(1.34)$ \\
\hline (Soh \& Leong, 2002) & 7.14 (1.15) & $6.91(1.25)$ & $7.15(1.20)$ & $5.46(1.64)$ \\
\hline
\end{tabular}


comparisons (Tukey's HSD) were performed for each significant dependent variable to assess where differences occurred. With horizontal collectivism as the dependent variable, significant differences were evident between the Māori sample and Urban Israeli and American samples, suggesting horizontal collectivism manifests differently in individuals from characteristically individualistic countries. Across the remaining dependent variables (HI, VC, VI) Māori differed significantly from the other sample populations, who did not differ significantly from each other.

\section{Self-Enhancement}

A further objective was to assess associations between the cultural orientations and self-enhancement. A series of standard multiple regressions were performed between the dependent variables of academic self-enhancement and the above-average effect, and horizontal collectivism (HC), horizontal individualism (HI), vertical collectivism (VC) and vertical individualism (VI). Each variable was tested for statistical analysis assumptions, prior to regressions being performed. Conventional yet conservative alpha levels (i.e., $p<.001$ ) were used to evaluate the significance of skewness and kurtosis (Tabachnik \& Fidell, 1989). No cases were found to be univariate outliers. Mahalanobis distance confirmed no cases were multivariate outliers with $p<.001$. Table 3 presents the results of the analyses, which display bivariate correlations between the variables, standardized regression coefficients $(\beta), R$, $R^{2}$, and adjusted $R^{2}$.

With academic self-enhancement as the dependent variable a significant model emerged, $F(4,54)=3.05, p$ $<.05$. Combined, the cultural orientations explain $18 \%$ ( $12 \%$ adjusted) of the variance. Horizontal collectivism made a significant contribution to academic selfenhancement in the expected direction, although none of the other cultural dimensions significantly contributed. This indicates horizontal collectivism is negatively related to academic self-enhancement, meaning the more horizontal collectivism is endorsed the less likely an individual is to express self-enhance-

Table 3

Standard Multiple Regressions of Cultural Orientations on Self-Enhancement and the Above-Average Effect

\begin{tabular}{lcccc}
\hline \multirow{2}{*}{ Variable } & \multicolumn{2}{c}{ Academic self-enhancement } & \multicolumn{2}{c}{ Above-average effect } \\
\hline & Pearson's $r$ & Beta & Pearson's $r$ & Beta \\
\hline $\mathrm{HC}$ & $-.36^{* *}$ & $-.47^{* *}$ & -.03 & .13 \\
$\mathrm{HI}$ & .07 & .01 & .04 & .06 \\
$\mathrm{VC}$ & .12 & .09 & -.10 & -.18 \\
$\mathrm{VI}$ & -.12 & .22 & -.26 & $-.28^{*}$ \\
$\mathrm{R}$ & $.43^{*}$ & & .30 & \\
$\mathrm{R}^{2}$ & $.18^{*}$ & & .09 & \\
Adjusted $\mathrm{R}^{2}$ & $.12^{*}$ & & .02 & \\
\hline
\end{tabular}

Note: ${ }^{*} p<.05,{ }^{* *} p<.01$ ment. With the above-average effect as the dependent variable, the model was not significant.

\section{Academic Intentions}

Just over $54 \%$ of participants indicated they sometimes thought about leaving the higher education institution they were studying at. Only $6 \%$ indicated they would definitely leave within the next year, while $40 \%$ indicated leaving was 'Not at all likely'.

A further multiple regression was performed to test whether academic self-enhancement and the aboveaverage effect predicted academic intentions. The model was nonsignificant, $F(2,54)=1.35, p=.27$, suggesting decisions to continue in higher education are not affected by self-enhancement. Rather, objective indicators of academic performance and abilities (e.g., exam results, grades) may be more influential in such decisions.

\section{Discussion}

The aims of this study were to: examine the cultural orientations in a New Zealand Māori sample; determine whether the orientations contribute to academic selfenhancement; and, investigate if self-enhancement affects intentions to continue higher education studies. We suggested horizontal collectivism would be prevalent in Māori, as the values underlying the culture are characteristic of this orientation. This hypothesis was supported. In line with previous work (e.g., Kurman, 2001; Kurman \& Sriram, 2002), we hypothesised selfenhancement would not be an important outcome for our sample, due to their horizontal collectivism. The results showed a significant negative relationship between the variables, suggesting the more horizontal collectivism was endorsed, the less likely participants were to self-enhance. The finding self-enhancement did not influence academic intentions, supported our final hypothesis. The findings, as well as limitations and theoretical, methodological, and practical implications are discussed below.

\section{Cultural Orientations}

Māori cultural values emphasise unity, connectedness, and relationships to significant others (e.g., kotahitanga, whanaungatanga). They also highlight integrity, equality and the forfeiting of one's own needs for those of others (e.g., utu, mana, tohatoha). These are congruent with collectivist and horizontal dimensions, which place importance on such attributes. The findings are comparable with Harrington and Liu (2002) who found Māori were oriented toward collectivism, in comparison to Pakehā . They are also comparable to Gouveia et al.'s (2003) study showing Spanish participants scored similarly high on horizontal collectivism compared to the other dimensions. Spanish society emphasises hospitality, communal sharing, and harmonious relationships (Fiske, 1992; Triandis et al., 1984). It is possible there is some 
degree of similarity between Māori and Spanish cultural values, although this is a question for future research.

Comparisons were made between the means of the present sample and other samples on each of the dimensions. Māori did not differ significantly on horizontal collectivism when compared to other collectivist samples, but did differ significantly on the other dimensions, scoring lower overall by comparison. The results suggest Māori are similar to other collectivist cultures on horizontal collectivism, and the emphasis placed on equality, cohesion, and others needs is characteristic of horizontal collectivist cultures. Despite being the indigenous culture of New Zealand, the effects of colonisation meant Māori are now a numerical minority in their own country. The majority of the New Zealand population comprises descendents of European settlers. Thus, New Zealand culture could be characterised as similar to other colonised and industrialised individualistic societies, such as Australia, America, and the United Kingdom. Despite being embedded in an individualistic culture, our results suggest traditional Māori values are still pertinent in this sample, as indicated by the horizontal collectivism findings.

When compared to individualistic cultures, the results were mixed. Our sample scored significantly lower on all of the dimensions, in contrast to European Americans and Americans, who scored highest on horizontal individualism and vertical collectivism, respectively. Urban Israeli's scored highest on horizontal individualism, and had a significantly lower score on horizontal collectivism in comparison to the other samples. With the exception of horizontal collectivism, Urban Israeli's scored higher than Māori on the other dimensions. Despite being immersed in a largely individualistic society, Māori have not completely assimilated the values of the mainstream culture (although there is likely to be some degree of assimilation), but rather adhere to the values of their culture, which reflect horizontal collectivism. The findings are also consistent with other studies reporting significant differences between individualist and collectivist samples (e.g., Kashiyama et al., 1995).

Individualism and collectivism are conceptualised as extreme dimensions on a continuum (Triandis \& Suh, 2002), and constitute two distinct cultural patterns (Triandis \& Gelfand, 1998). Correlational analyses showed the individualist dimensions were not significantly related, although horizontal and vertical collectivism did share a significantly positive association. These findings are consistent with previous studies (e.g., Singelis et al., 1995; Soh \& Leong, 2002; Triandis \& Gelfand, 1998), and add to the proposition the individualist cultural orientations are distinct constructs. The relationship between the collectivist dimensions was moderate $(r=.55)$ and comparable to other populations. This suggests the dimensions are tapping into collectivism in some systematic way, although the strength of the relationship implies there is some differentiation between horizontal and vertical facets.

Overall, the findings regarding the cultural orientations have a number of implications. They advance the individualism/collectivism literature by suggesting the cultural orientations are evident within this New Zealand Māori sample, and are comparable to previous research (e.g., Harrington \& Liu, 2002). Earlier research (e.g., Green et al., 2005; Hartung et al., 2010; Oyserman et al., 2002) suggests populations perceived as similar, often express differently or do not share the same degree of individualism/collectivism and verticality/horizontalism (e.g., Asian cultures typically show different degrees of horizontal collectivism). The values underlying Māori culture mean the degree of horizontal collectivism is expressed differently to other horizontal collectivist cultures. Future research may explore this issue further by making cross-cultural comparisons between our sample and those of other countries, to determine where differences lie in terms of the expression of each dimension.

The findings also give insight into the endurance of some Māori values, despite the advent of acculturation historically experienced by Mãori. We suggested Māori are horizontal collectivists because some very specific values still have importance to some individuals affiliating to the culture. Previous studies show Pākehā New Zealanders are likely to be individualistic in orientation rather than collectivistic (e.g., Harringotn \& Liu, 2002; Hewson, 2002). Others show some Māori samples do not differ from Pākehā in their orientation to culture, and this may be explained by the level of acculturation, or 'diverse realities' of participants (Shulruf et al., 2007). Future research might examine the cultural orientations in a wider New Zealand sample, which includes both Māori and non-Māori participants, varying in age, gender, area of residence, and socio-economic, educational, and professional statuses. Comparisons between both cultural groups according to such variations will allow more definitive conclusions regarding the degree of individualism/collectivism and verticality/horizontalism in New Zealand Māori, and whether level of acculturation has an influence.

Following from this, it would also be interesting to examine whether there are differences in the dimensions among Māori. Our sample was restricted in that it comprised mainly Māori women above the age of 40, who were studying toward a higher qualification at university. Māori participation in higher education is around 20\% (Ministry of Education, 2007), thus highlighting how limited our sample was. Our participants were all bursars of a Māori-specific program. Given these factors, the participants were likely to have greater exposure to Māori cultural processes, making Māori values readily available in conscious awareness. Our sample may therefore have more strongly identified with the values we believed per- 
tinent to a horizontal collectivist orientation. Future research might explore whether other sub-populations in Māori culture share the same degree of horizontal collectivism as our sample. Given the widely recognised notion of 'diverse realities' (Durie, 2008), it would be interesting to examine whether differences occur between younger and older Māori, Māori with and without higher education qualifications, and those living in more rural vs. urban environments, among others. The extent of exposure to Mãori cultural values, is likely to impact the degree each cultural dimension is expressed. Acculturation is a proposed explanation for intra-group differences in some ethnic samples (e.g., Hartung et al., 2010), so may also apply to Māori.

\section{Self-Enhancement}

Academic self-enhancement and the above-average effect were the measures used to assess self-enhancement in the present study. The sample had overall high mean scores on both of these measures, suggesting they do feel good about themselves in terms of their academic abilities. Given these high mean scores, we wanted to see whether the cultural orientations played a part in the expression of self-enhancement.

Previous research shows self-enhancement is predicted by the cultural orientations, specifically individualism (Kurman, 2001). Our findings indicate in combination the dimensions explained $18 \%$ of the variance in academic self-enhancement, although only horizontal collectivism made a significant contribution. This contrasts to previous findings of no relationship between horizontal collectivism and self-enhancement (e.g., Kurman \& Sriram, 2002). As predicted, the relationship found in the present study was negative, suggesting the more horizontal collectivism is endorsed, the less likely one is to academically self-enhance. This makes sense within the context of Māori culture, where values like mana and whakaiti dissuade an individual from promoting their positive characteristics.

The findings may also be viewed from another perspective. A number of studies have found self-enhancement exists in collectivist cultures (e.g., Heine \& Hamamura, 2007), but as Kurman (2001) suggests, its expression is restricted by cultural demands. The sample had high mean scores on the self-enhancement measure, suggesting selfenhancement does exist within the sample. High mean scores on horizontal collectivism suggest participants endorsed values of equality, integrity, and respect for others. These findings support Kurman's (2001) view selfenhancement exists in collectivist cultures, such as Māori, although it may be that cultural restrictions prevent its open expression.

In that sense, the academic self-enhancement measure used in this study could be assessing selfenhancement as an external expression, as opposed to an internal feeling, which might account for the negative relationship between the constructs in our regression analyses. This issue could be explored in future research. It may be useful to examine the way self-enhancement is measured. If self-enhancement does exist in collectivist cultures as suggested by Kurman (2001), it would be important to examine ways it may be better conceptualised to reflect self-enhancement as both an externally expressed and internally felt phenomenon.

It may also be that self-enhancement is intimately intertwined with other-enhancement in collectivist cultures. Given the needs of the self can be secondary to the needs of significant others in such cultures, the notion of enhancing oneself may not be important or be nonexistent. This could be a fruitful area to explore in future research, as would developing a measure of self- vs. other-enhancement that could be used cross-culturally to examine the validity of this proposition.

A related issue concerns the accuracy of academic self-enhancement measurements (Assor, Tzelgov, Thein, Ilardi, \& Connell, 1990; Kenny \& Albright, 1987). Selfratings of academic ability are often compared to an individual's actual academic grades. While this appears to be a reasonable assessment of how an individual views their abilities, is it a sure indicator of an individual's tendency to self-enhance? If an individual positively rates their academic ability and a comparison of their academic grades indicates such a rating is accurate, is the rating indicative of a tendency to self-enhance or a realistic assessment of ability? Alternatively, if an individual rates their academic ability positively but their academic grades indicate the rating is an excessively positive assessment with no basis in reality, is the rating indicative of self-enhancement or for example, the self-aggrandizement characteristic of individuals with narcissistic personality disorder (Kaplan \& Sadock, 1998)?

Presumably, the two types of ratings result from differences in the psychological functioning of individuals, which are unrelated to an ability to maintain a positive appraisal of oneself. However, consensus regarding the underlying meanings of the two types of assessment, and which type best constitutes and accurately captures the concept of self-enhancement is lacking, but provides a fruitful area for future investigation.

Kurman (2001) also suggests the culturally desirable need to express modesty inhibits the expression of selfenhancement in collectivist societies. It is possible the desire for modesty is applicable in Māori culture, thus dissuading the expression of self-enhancement. Specifically, the value of whakaiti, which literally translates as to become small, emphasises the importance placed on individuals to be modest and humble about their own achievements. Future research could examine whether a need for modesty within Māori culture, as espoused through the value of whakaiti, plays a role in the relationship between horizontal collectivism and the expression of self-enhancement. 
When the above-average effect was used as the measure of self-enhancement, only vertical individualism made a significantly negative contribution, indicating the more vertical individualistic attributes are endorsed, the less likely one is to possess the aboveaverage effect. The above-average effect assesses whether an individual believes themselves to be better than average in comparison to others. Vertical individualism emphasises success, status, and hierarchy through competition with others. An assumption was these variables would be positively related, so the finding of a negative relationship in our regression analyses is surprising.

However, this may be explained by the characteristics of the sample, which comprised individuals who selfidentified as Māori and were recipients of a Māori-specific bursary for higher education. Receiving this bursary suggests these individuals participated in activities with Māori values as the underlying ethos, in addition to being immersed in a competitive higher education environment. An explanation of the relationship between vertical individualism and the above-average effect is that those who endorsed vertical individualism were competitive in terms of their educational success, but still exposed to Māori values such as mana and whakaiti, which influenced them in such a way as to inhibit expression of the above-average effect. As mentioned previously, the present sample limits the extent generalisations can be made from the findings. However, future research could address this limitation by sampling a wider stratum of participants, and determining whether the results regarding the above-average effect in this study are mirrored in other studies with more diverse samples.

\section{Academic Intentions}

We assessed whether academic self-enhancement and the above-average effect predicted participants intentions to continue participating in higher education studies. We assumed the relationship between these variables would be positive, as those who feel good about their academic abilities and believe they are above-average in terms of academic achievement are more likely to continue with higher education studies. Lower academic self-enhancement is unlikely to be a motivating factor for continued study. Because we hypothesised Māori are horizontal collectivists, and thus less likely to self-enhance, does not mean we thought they were more likely to leave academic studies. Instead, we thought perceptions regarding one's abilities would not play a part in whether participants intended to leave or remain within the higher education environment. Results indicated neither of the constructs was significantly related, suggesting the expression of self-enhancement does not affect decisions to continue participating in higher education.

Jefferies (1997) stated issues such as financial difficulties, inappropriate support systems, and isolation serve as barriers to Māori participation in higher education, and may have the additional consequence of creating negative perceptions about one's abilities and potential within educational environments. All participants in the present study were recipients of a bursary providing financial, pastoral, and academic support to complete higher education qualifications. Participation in this program would have decreased the mentioned barriers and the associated psychological consequences. This then influenced decisions to continue studying, irrespective of whether participants self-enhanced or not, thus explaining the lack of impact self-enhancement had on academic intentions.

This finding contrasts with Malezer's (1992) 'sink or swim' theory, which suggests students who maintain a sense of their cultural identity tend not to do well in higher education environments (i.e., they sink), while those who wish to succeed will forfeit their cultural identity to achieve success (i.e., they swim). Our results indicate students with a sense of their Māori cultural identity (as highlighted by the endorsement of horizontal collectivism) are able to maintain positive attitudes toward their higher education studies, as reflected in their intentions to continue participating. It is likely the support received from the bursary program played an important role in enhancing connections to Māori culture for the participants, as well as facilitating achievements in higher education studies.

Future research could examine whether selfenhancement is important to higher education participation in Māori who do not have the same opportunities available (i.e., do not have a bursary), or the same life experiences. For example, Māori students who are not financially supported to study may rely more on a positive view of their abilities, when deciding to continue or engage in higher education. In our study, objective criteria such as exam results and final grades may have been more influential in determining academic decisions, than how participants felt about their academic abilities. Examining the relevance of objective criteria to academic intentions would be important for furthering knowledge in the area, and it is possible both objective and subjective (i.e., psychological) factors interact to affect decisions regarding future participation in higher education studies.

\section{Conclusion}

Individualism and collectivism are the most widely studied cultural characteristics (Brewer \& Chen, 2007; Green et al., 2005; Singelis et al., 1999). Although there are still many limitations inherent to the use of these constructs, they do serve as a useful starting-point for examining cultural diversity around the globe. The findings of the present research show the cultural orientations are applicable to the New Zealand Māori cultural group, and support the findings of some previous research (e.g., 
Harrington \& Liu, 2002), thus creating a variety of avenues for future research. Although previous studies have shown self-enhancement is important for some cultures, our results suggest self-enhancement, at least as an external expression is not related to individualism and collectivism. As we have suggested, this may be a consequence of the way self-enhancement is currently assessed, so other possibilities for the measurement of the construct should be explored and applied to similar samples. Self-enhancement also did not contribute to educational intentions, although this may be explained by the demographic and unique opportunity available to the sample (i.e., receiving a bursary). Māori rates of participation in higher education continue to increase, and currently exceed participation rates of other ethnic groups in New Zealand (Ministry of Education, 2007). Ascertaining factors contributing to this increase is important for predicting future participation rates, as this will undoubtedly contribute to policy development and implementation. The present research provides a foundation from which to further explore some of these factors.

\section{References}

Assor, A., Tzelgov, J., Thein, R., Ilardi, B.C., \& Connell, P. (1990). Assessing the correlates of over- and underrating of academic competence. A conceptual clarification and methodological proposal. Child Development, 61, 20852097.

Atwater, L., Wang, M., Smither, J.W., \& Fleenor, J.W. (2009). Are cultural characteristics associated with the relationship between self and others' ratings of leadership? Journal of Applied Psychology, 94, 876-886.

Bennett, S.T. (2001). Cultural identity and academic achievement of Māori undergraduate university students. Unpublished Masters thesis, Massey University, Palmerston North, New Zealand.

Bochner, S. (1994). Cross-cultural differences in the selfconcept: A test of Hofstede's individualism/collectivism distinction. Journal of Cross-Cultural Psychology, 25, 273283.

Bonanno, G.A., Rennicke, C., \& Dekel, S. (2005). Self-enhancement among high-exposure survivors of the September 11th terrorist attack: Resilience or social maladjustment? Journal of Personality and Social Psychology, 88, 984-998.

Brewer, M.B., \& Chen, Y. (2007). Where (who) are collectives in collectivism? Toward conceptual clarification of individualism and collectivism. Psychological Review, 114, 133-151.

Brown, J.D. (1998). The self. New York: McGraw-Hill.

Church, T., Katigbak, M. S., del Prado, A.M., Valdez-Medina, J.L., Miramontes, L.G., \& Ortiz, F.A. (2006). A cross-cultural study of trait self-enhancement, explanatory variables, and adjustment. Journal of Research in Personality, 40, 1169-1201.

Coon, H.M., \& Kemmelmeier, M. (2001). Cultural orientations in the United States. (Re)Examining differences among ethnic groups. Journal of Cross-Cultural Psychology, 32, 348-364.
Durie, M. (2001). Mauri ora: The dynamics of Māori health. Auckland: Oxford University Press.

Durie, M. (2008, December). Bioethics in research: The ethics of indigeneity. Paper presented at the 9th Global Forum on Bioethics in Research, Auckland, New Zealand.

Elsmore, B. (1989). Mana from heaven: A century of Māori prophets in New Zealand. Wellington, New Zealand: Moana Press.

Fiske, A.P. (1992). The four elementary forms of sociality: Framework for a unified theory of social relations. Psychological Review, 99, 689-723.

Gouveia, V.V., Clemente, M., \& Espinosa, P. (2003). The horizontal and vertical attributes of individualism and collectivism in a Spanish population. The Journal of Social Psychology, 143, 43-63.

Green, E.G.T., Deschamps, J-C., \& Paez, D. (2005). Variation of individualism and collectivism within and between 20 countries. Journal of Cross-Cultural Psychology, 36, 321399.

Greenfield, P.M. (1999). Three approaches to the psychology of culture: Where do they come from? Presented at the third conference of the Asian Association of Social Psychology, Taiwan.

Gushue, G.V., \& Constantine, M.G. (2003). Examining individualism, collectivism, and self-differentiation in African American college women. Journal of Mental Health Counselling, 25, 1-15.

Harrington, L., \& Liu, J.H. (2002). Self-enhancement and attitudes toward high achievers: A bicultural view of the independent and interdependent self. Journal of CrossCultural Psychology, 33, 37-55.

Hartung, P.J., Fouad, N.A., Leong, F.T.L., \& Hardin, E.E. (2010). Individualism-collectivism: Links to occupational plans and work values. Journal of Career Assessment, 18, $34-45$.

Heine, S.J., \& Hamamura, T. (2007). In search of East Asian self-enhancement, Personality and Social Psychology Review, $11,4-27$.

Heine, S.J., Kitayama, S., \& Lehman, D.R. (2001). Cultural differences in self-evaluation: Japanese readily accept negative self-relevant information. Journal of Cross-Cultural Psychology, 32, 434-443.

Heine, S.J., \& Lehman, D.R. (1997). The cultural construction of self-enhancement: An examination of group serving biases. Journal of Personality and Social Psychology, 72, $1268-1283$.

Heine, S.J., Lehman, D.R., Markus, H.R., \& Kitayama, S. (1999). Is there a universal need for positive self-regard? Psychological Review, 106, 766-794.

Henare, M. (1988). Nga tikanga me nga ritenga o te ao MāoriStandards and foundations of Māori society. Royal Commission on Social Policy, 3, 39-69.

Hewson, D.A. (2002). Individualism and collectivism: A comparison of Māori and Pākehā self-concepts. Unpublished masters thesis, Waikato University, Hamilton, New Zealand. 
Jefferies, R. (1997). Māori participation in tertiary education: Barriers and strategies to overcome them. Wellington, New Zealand: Te Puni Kōkiri.

Jetten, J., Postmes, T., \& Mcauliffe, B.J. (2002). 'We're all individuals': Group norms of individualism and collectivism, levels of identification and identity threat. European Journal of Social Psychology, 32, 189-207.

Kaplan, H.I., \& Sadock, B.J. (1998). Synopsis of psychiatry. Behavioral sciences/Clinical psychiatry (8th ed.). Baltimore: Lippincott Williams and Wilkins.

Kashiyama, Y., Yamaguchi, S., Kim, U., Choi, S., Gelfand, M.J., \& Yuki, M. (1995). Culture, gender, and self: A perspective from individualism-collectivism research. Journal of Personality and Social Psychology, 69, 925-937.

Kemmelmeier, M., Burnstein, E., Genkova, K.K.P., Kanagawa, C., Hirshberg, M.S., Erb, H.P., Wieczorkowska, G., \& Noels, K. A. (2003). Individualism, collectivism, and authoritarianism in seven societies. Journal of Cross-Cultural Psychology, 34, 304-322.

Kenny, D.A., \& Albright, L. (1987). Accuracy in interpersonal perception: A social relations analysis. Psychological Bulletin, 102, 390-402.

Kitayama, S., Markus, H.R., \& Kurokawa, M. (2000). Culture, emotion, and well-being: Good feelings in Japan and the United States. Cognition and Emotion, 14, 93-124.

Kitayama, S., Markus, H.R., Matsumoto, H., \& Norasakkunkit, V. (1997). Individual and collective processes in the construction of the self: Self-enhancement in the United States and self-criticism in Japan. Journal of Personality and Social Psychology, 72, 1245-1267.

Kobayashi, C., \& Brown, J.D. (2003). Self-esteem and selfenhancement in Japan and America. Journal of Cross-Cultural Psychology, 34, 567-580.

Kurman, J. (2001). Self-enhancement: Is it restricted to individualistic cultures? Personality and Social Psychology Bulletin, 27, 1705-1716.

Kurman, J. (2003). Why is self-enhancement low in certain collectivist cultures? An investigation of two competing explanations. Journal of Cross-Cultural Psychology, 34, 496510.

Kurman, J., \& Eshel, Y. (1998). Self-enhancement, generality level of self-evaluation, and emotional adjustment. The Journal of Social Psychology, 138, 549-563.

Kurman, J., \& Sriram, N. (2002). Interrelationships among vertical and horizontal collectivism, modesty, and self-enhancement. Journal of Cross-Cultural Psychology, 33, 71-86.

Kurman, J., Yoshihara-Tanaka, C., \& Elkoshi, T. (2003). Is selfenhancement negatively related to constructive self-criticism? Self-enhancement and self-criticism in Israel and in Japan. Journal of Cross-Cultural Psychology, 34, 2437.

Malezer, B. (1992). Academic culture and Murris' education. In C. White (Ed.), Towards 2000: Maintaining the momentum, Proceedings of the National Aboriginal and Torres Strait Islander Higher Education Conference, Hervey Bay, Queensland, University of Southern Queensland, Australia.
Markus, H.R., \& Kitayama, S. (1991). Culture and the self: Implications for cognition, emotion, and motivation. Psychological Review, 98, 224-253.

Markus, H.R., \& Kitayama, S. (1994). A collective fear of the collective: Implications for selves and theories of selves. Personality and Social Psychology Bulletin, 20, 568-579.

Mental Health Commission. (2003). Report on progress 20012002: Towards implementing the Blueprint for Mental Health Services in New Zealand. Wellington: Mental Health Commission.

Metge, J. (1995). New growth from old: The whannau in the modern world. Wellington: Bridget Williams Books.

Ministry of Education. (2007). Māori participation in tertiary education 2005. February 2007 (Fact Sheet produced for the Tertiary Sector Performance Analysis \& Reporting). Wellington, New Zealand: Author.

Nelson, M.R., \& Shavitt, S. (2002). Horizontal and vertical individualism and achievement values. A multimethod examination of Denmark and the United States. Journal of Cross-Cultural Psychology, 33, 439-458.

Oishi, S., Schimmack, U., Diener, E., \& Suh, E.M. (1998). The measurement of values and individualism-collectivism. Personality and Social Psychology Bulletin, 24, 1177-1190.

Oyserman, D., Coon, H.M., \& Kemmelmeier, M. (2002). Rethinking individualism and collectivism: Evaluation of theoretical assumptions and meta-analyses. Psychological Bulletin, 128, 3-72.

Ozdikmenli-Demir, G., \& Sayil, M. (2009). Individualism-collectivism and conceptualisations of interpersonal relationships among Turkish children and their mothers. Journal of Social and Personal Relationships, 26, 371-387.

Schwartz, S. H. (1990). Individualism-collectivism: Critique and proposed refinements. Journal of Cross-Cultural Psychology, 21, 139-157.

Shulruf, B., Hattie, J., \& Dixon, R. (2007). Development of a new measurement tool for individualism and collectivism. Journal of Psychoeducational Assessment, 25, 385-401.

Singelis, T.M., Bond, M.H., Sharkey, W.F., \& Siu Yiu Lai, C. (1999). Unpacking culture's influence on self-esteem and embarrassability. The role of self-construals. Journal of Cross-Cultural Psychology, 30, 315-341.

Singelis, T.M., Triandis, H.C., Bhawuk, D.P.S., \& Gelfand, M.J. (1995). Horizontal and vertical dimensions of individualism and collectivism: A theoretical and measurement refinement. Cross-Cultural Research, 29, 240-275.

Snibbe, A.C., Kitayama, S., Markus, H.R., \& Suzuki, T. (2003). They saw a game. A Japanese and American (football) field study. Journal of Cross-Cultural Psychology, 34, 581-595.

Soh, S., \& Leong, F.T.L. (2002). Validity of vertical and horizontal individualism and collectivism in Singapore: Relationships with values and interests. Journal of CrossCultural Psychology, 33, 3-15.

Statistics New Zealand. (2007). Quick stats about Māori. Retrieved 22 September 22, 2009, from http://www.stats. govt.nz/ /media/statistics/publications/census/ 2006census-reports/quickstats-about-a-subject/ maori/qstats-about-maori-2006-census.aspx. 
Strunk, D.R., \& Chang, E.C. (1999). Distinguishing between fundamental dimensions of individualism-collectivism: Relations to sociopolitical attitudes and beliefs. Personality and Individual Differences, 27, 665-671.

Tabachnik, B., \& Fidell, L. (1989). Using multivariate statistics (2nd ed.). Toronto, CA: Harper Collins Publishers.

Te Rau Puawai. (2004). Māori mental health career opportunities. Retrieved May 31, 2004, from http://te-rau-puawai. massey.ac.nz/general/index.html.

Thomas, D.C., \& Perkerti, A.A. (2003). Effect of culture on situational determinants of exchange behaviour in organizations. A comparison of New Zealand and Indonesia. Journal of Cross-Cultural Psychology, 34, 269281.

Triandis, H.C. (1990). Cross-cultural studies of individualism and collectivism. In J. Berman (Ed.), Nebraska symposium on motivation, 1989 (pp. 41-133). Lincoln, NE: University of Nebraska Press.

Triandis, H.C. (1995). Individualism and collectivism. Boulder, CO: Westview Press.

Triandis, H.C., \& Gelfand, M.J. (1998). Converging measurement of horizontal and vertical individualism and collectivism. Journal of Personality and Social Psychology, $74,118-128$.

Triandis, H.C., Marin, G., Lisansky, J., \& Betancourt, H. (1984). Simpatia as a cultural script of Hispanics. Journal of Personality and Social Psychology, 47, 1363-1375.

Triandis, H.C., \& Suh, E.M. (2002). Cultural influences on personality. Annual Review of Psychology, 53, 133-160.

Walker, S., Eketone, A., \& Gibbs, A. (2006). An exploration of kaupapa Māori research, its principles, processes and applications. International Journal of Social Research Methodology, 9, 331-344. 